\title{
Russian academy leader speaks out on reforms
}

\section{Vladimir Fortov highlights the need for a clear separation between science and administration.}

\section{Quirin Schiermeier}

20 September 2013

A reform bill approved earlier this week by Russia's lower parliamentary chamber, the State Duma, has thrown the Russian Academy of Sciences (RAS) into turmoil. Physicist Vladimir Fortov (pictured), recently elected president of the academy, speaks to Nature about the delicately poised situation, which is likely to see the RAS come under the control of a federal agency that reports directly to President Vladimir Putin (see 'Vote seals fate of Russian Academy of Sciences').

Some commentators have said that the RAS has ceased to exist. Is that so?

I don't quite agree. The first version of the reform bill, drafted in June, would indeed have resulted in our liquidation. But the version of the law that the Duma adopted on Wednesday has been amended in several respects. I'm not happy at all with that law,

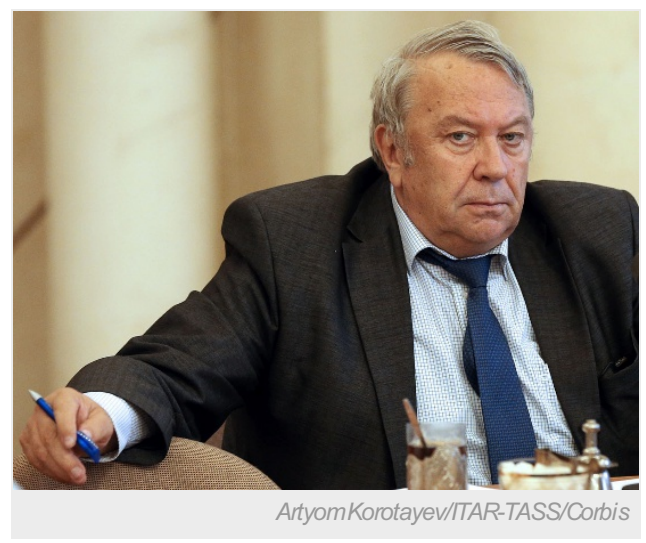
but it allows us to continue to exist as a learned body of outstanding scientists.

\section{So what will change?}

Our methods of operation will change and our institutes will be owned by a federal agency. But I hope that science will operate separately from that agency.

\section{What are your main concerns?}

In future, scientific directors will be appointed jointly by the RAS and the new agency. It's supposed to be a compromise, but it's not a good solution and it could be very bad for science in our country. We [the RAS general assembly] had hoped and suggested [in August] that the academy would be responsible for science, whereas the federal agency would solely be responsible for property management. Disappointingly, our proposals were not adopted. But we must still insist on a clear and sharp separation of the two spheres.

Who will decide who is responsible?

Much depends on who will head the new agency. Putin has said that [the head] will be the president of the RAS. But the adopted law has no such provision. So, theoretically, a bureaucrat or government official could be put in charge, which I think would be a very bad thing for us. We must wait and see what happens. I understand that, at least in the transition period, I will remain responsible for science.

\section{When will we know the final outcome?}

There's no clear timetable yet for how the new law will be implemented. The upper chamber of parliament is scheduled to discuss the law on 25 September - I hope we will have clarification thereafter.

You took office in May this year. Will you resign if things run against you?

It is possible, but it is too early to say.

What do you think of media reports that there will be a three-year moratorium on the election of new academy members?

This is not the case. The new law says no such thing. 
Are you afraid that scientists might lose their jobs?

I don't know. The government will formulate targets. We have been asked to become more efficient - that's all I can say. These are difficult times for us. We will consult with academies in other countries and we're grateful for any support we get.

Nature | doi:10.1038/nature.2013.13791 